\title{
Estudio diacrónico de animum inducere e in animum inducere: convergencias y diferencias ${ }^{*}$
}

\author{
José Miguel Baños \\ Universidad Complutense de Madrid \\ jmbanos@ucm.es \\ ORCID iD: https://orcid.org/0000-0002-7324-5696
}

\section{A Diachronic Study of animum inducere and in animum inducere: Convergences and Differences}

El objetivo de este artículo es analizar las características semánticas y sintácticas, la frecuencia de empleo y la evolución diacrónica de dos construcciones con verbo soporte semánticamente similares pero sintácticamente distintas: animum inducere e in animum inducere ('tomar una decisión', 'decidir', 'considerar'). Para explicar su origen, diferencias y evolución, se ponen en relación con otras construcciones como animum aduertere, in animo habere e in animo esse.

Palabras clave: colocaciones; verbo soporte; sintaxis; latín; (in) animum inducere.
The aim of this paper is to analyze the semantic and syntactic characteristics, the frequency of use and the diachronic evolution of two support verb constructions that are semantically similar but syntactically different: animum inducere and in animum inducere ('make a decision', 'decide', 'consider'). In order to explain their origin, differences and diachronic evolution, they are put in relation to other support verb constructions: animum aduertere, in animo habere and in animo esse.

Key words: collocations; support verb; syntax; Latin; (in) animum inducere.

Cómo citar este artículo / Citation: Baños, José Miguel (2021): «Estudio diacrónico de animum inducere e in animum inducere: convergencias y diferencias», Emerita 89 (2), pp. 279-307.

* Este trabajo se inserta en los Proyectos de Investigación «Interacción del léxico y la sintaxis en griego antiguo y en latín: construcciones con verbo soporte» (FFI2017-83319-C-3), financiado por el Ministerio de Ciencia e Innovación; y «Diccionario de colocaciones latinas en la red (DiCoLat)», del Programa Logos-Fundación BBVA. Mi agradecimiento a dos informantes anónimos por su atenta lectura, sus sugerencias y aportaciones.

Copyright: (C) 2021 CSIC. Este es un artículo de acceso abierto distribuido bajo los términos de la licencia de uso y distribución Creative Commons Reconocimiento 4.0 Internacional (CC BY 4.0). 


\section{INTRODUCCIÓN}

\section{El marco predicativo del verbo inducere}

El verbo inducere ('conducir hacia', 'hacer entrar', 'introducir'), como otros verbos causativos de movimiento (cf. Pinkster 2015, p. 178), presenta un marco predicativo triargumental: un sujeto habitualmente personal, un objeto directo (OD) concreto en acusativo y un complemento de dirección, por lo general expresado con in o ad + acus.:

(1) cum exercitum in Macedoniam induceret («después de introducir el ejército en Macedonia», Liu. XXXI 28.2).

De este marco predicativo básico, como realizaciones más metáforicas o abstractas, se derivan otros empleos de inducere en los que, bien la casilla del OD (2), bien la del complemento de dirección, aparecen ocupadas por sustantivos abstractos (3), por una subordinada con $u t+$ subjuntivo (4) o por un infinitivo prolativo $^{1}(5)$ :

(2) in ciuitatem inducunt seditionem atque discordiam («introducen en la patria la sedición y la discordia», Cic., off. I 85).

(3) ad misericordiam inducitur, ad pudendum, ad pigendum («es inducido a la compasión, a la vergüenza, al arrepentimiento», Cic., Brut. 188).

(4) Quem ego ut mentiatur inducere possum, ut peieret exorare facile potero («A quien yo pueda inducir a que mienta, fácilmente lo podré mover a que jure en falso», Cic., Rosc. com. 46).

(5) Placitum dehinc non ultra cunctari, sed designatum consulem Mammium Pollionem ingentibus promissis inducunt sententiam expromere ( «Con grandes promesas inducen al cónsul designado Mammio Polión a presentar una propuesta», Tac., ann. XII 9).

${ }^{1}$ Frente a las completivas de Acusativo con Infinitivo (AcI), con el término infinitivo prolativo se hace referencia, entre otros, a los infinitivos «goberned by modal and phasal verbs» (Pinkster 2015, p. 526), del tipo qui potuit uidere? («¿cómo pudo verlo?», Plaut., Mer. 183) o dependientes de verbos de tres posiciones, del tipo admoneo te ire («te aconsejo ir»). En este último contexto, dichos infinitivos pueden alternar con $u t+$ subj. y con sintagmas preposicionales «with ad or in in combination with a noun that implies an event» (Pinkster 2015, p. 183). 


\section{La colocación animum inducere}

Es a partir de este tipo de contextos cuando se configuran determinadas colocaciones verbo-nominales con inducere. Así, por ejemplo, in errorem inducere de (6) presenta la perspectiva causativa ('inducir a error' = 'equivocar') de la construcción con verbo soporte in errorem incidere / cadere ('caer en un error' = 'equivocarse'), tal como ilustran los ejemplos (7) y (8):

(6) ita laudauisti quosdam oratores ut imperitos posses in errorem inducere («has alabado tanto a algunos oradores, que podrías inducir a error a los inexpertos», Cic., Brut. 293).

(7) plerique autem ... i maximum errorem inciderunt («la mayoría de ellos ... cayeron en un gravísimo error», Quint. inst. II 15.24).

(8) numquam in hunc ceciderunt errorem («nunca cayeron en este error», Quint. inst. V 12.21).

Pues bien, a partir de estos contextos surge también la colocación animum inducere ('tomar una decisión', 'decidir', 'considerar'), plenamente gramaticalizada, como veremos (§ III.1), ya desde el latín arcaico.

Dos ejemplos puente sirven para entender su origen. Así en el ejemplo (9), la atención, el propósito (animum) del sujeto se dirige hacia un objetivo expresado por un sustantivo concreto (ad meretricem), mientras que en (10) ese objetivo ya es plenamente abstracto (in spem):

(9) Nunc animum rursum ad meretricem induxti tuom («Pero ahora has vuelto a poner tu corazón en la cortesana», Ter., Hec. 689).

(10) Non est igitur amici talem esse in eum, qualis ille in se est, sed potius eniti et efficere, ut amici iacentem animum excitet inducatque in spem cogitationemque meliorem («no es propio de un amigo ser para con estos tal como ellos son para consigo mismos, sino que más bien hay que esforzarse en lograr levantar el ánimo abatido del amigo, y llevarlo a una esperanza y a unas ideas mejores», Cic., Lael. 59).

En realidad, ejemplos como (9) y (10) son excepcionales en latín, ya que con animum inducere lo habitual es que, en lugar de un sintagma preposicional directivo, como tercer argumento aparezca bien una subordinada conjuncional con $u t / n e+$ subj. como en (11), bien un infinitivo prolativo, como en (12): 
(11) animum ego inducam tamen / ut illud quem <ad modum $>$ tuam in rem bene conducat consulam ( «sin embargo, me haré a la idea de que debo pensar solo en tus intereses», Plaut., Cist. 633-634).

(12) ego numquam credidi / fore, ut ille hac uiua posset animum inducere / uxorem habere («jamás pensé que, estando ella viva, él pudiera tomar la decisión de casarse», Ter., Hec. 99-100).

Animum inducere en los ejemplos de (11) y (12) es, pues, una construcción con verbo soporte (CVS a partir de ahora) ${ }^{2}$, es decir, una colocación verbo-nominal restringida léxicamente ${ }^{3}$, un predicado verbal analítico que se entiende con un sentido unitario (como en español 'tomar una decisión') y del que dependen los distintos tipos de subordinadas completivas: $u t+$ subj. (11) e infinitivo prolativo (12).

\section{La colocación in animum inducere}

Ocurre, sin embargo, que, de forma paralela a animum inducere, se documenta también en latín, desde época arcaica, la CVS in animum inducere, que los diccionarios (Lewis y Short, Gaffiot, Glare) o el Thesaurus Linguae Latinae (s. u. animus) consideran sinónima, ya que presenta el mismo tipo de subordinadas dependientes y con el mismo significado. Así, por ejemplo, en el diccionario de Lewis y Short 1879, s. u., se puede leer en la entrada de animus: «inducere in

2 A lo largo del artículo empleo la expresión «construcción con verbo soporte» en sentido amplio (Baños 2016, 2021a), para referirme a aquellas colocaciones constituidas por un sustantivo abstracto (con estructura argumental propia) y un verbo que aporta las categorías de tiempo, modo, voz o persona para que dicho sustantivo se convierta en el núcleo de un predicado analítico: iter facere, odio habere, in mentem uenire, etc. Este concepto amplio es el que adopta, por ejemplo, G. Gross (2004, p. 357), para el análisis en francés de las colocaciones con sustantivos como combat o guerre, y coincide en gran medida con el término Funktionsverbgefüge de Hoffmann 1996, o los «composite predicates» de Rosén 2020. Cf., en este mismo sentido, Pinkster 2015, pp. 74-77, quien, por ejemplo, considera CVS in obliuionem uenire, un predicado analítico similar a in animum inducere. Para una visión más restringida del término, cf. Martín Rodríguez 2018. En Mendózar 2020 se ofrece un completo estado de la cuestión sobre las CVS en latín, con múltiples referencias.

${ }^{3}$ Así, los 66 ejemplos de in animum documentados en el corpus del Packard Humanities Institute (PHI) hasta s. II d. C. aparecen repartidos entre 22 verbos distintos. Pues bien, más de la mitad de dichos ejemplos (en concreto, 38, es decir, el 57,6\%) depende exclusivamente de inducere. Hay, por tanto, una evidente selección léxica restringida. 
animum or animum, to resolve upon doing something». Y en la de induco: «[inducere] animum or in animum, to bring one's mind to, to resolve, determine; to suppose, imagine». Y en Gaffiot 2016, s. u. induco: «animum inducere, prendre sur soi, se mettre en tête, se résoudre ... || in animum inducere même sens».

En efecto, a la vista de ejemplos de in animum inducere como los (13) y (14), no resulta fácil establecer diferencias de significado y de construcción sintáctica - de nuevo una completiva conjuncional en (13) o un infinitivo prolativo en (14)_, con los ejemplos previos y paralelos de (11) y (12) con animum inducere:

(13) Induxi in animum, ne oderim item ut alias, quando orasti («He tomado la decisión de no despreciarla como a las demás, ya que me lo has pedido», Plaut., Mil. 1269).

(14) nemo alteri concedere in animum inducebat («nadie se decidía a ceder en pro de otro», Liu. I 17.4).

\section{Dos colocaciones sintácticamente distintas}

En realidad, las dos CVS se integran en el marco predicativo trivalente de inducere ( $\S$ I.1) pero en posiciones sintácticas distintas, tal como he intentado reflejar en el Cuadro 1, en el que animum inducere e in animum inducere se ponen en relación con empleos no colocativos de inducere como los ilustrados previamente:

Cuadro 1: posibilidades sintácticas del marco predicativo triargumental de inducere

\begin{tabular}{|l|l|l|l|}
\hline \multicolumn{1}{|c|}{$3^{\circ}$ argumento } & \multicolumn{1}{c|}{ OD } & \\
\hline$(1)$ & in Macedoniam & exercitum & inducere \\
\hline$(3)$ & ad misericordiam, ad pudendum & aliquem & inducere \\
\hline$(4)$ & ut mentiatur & aliquem & inducere \\
\hline$(5)$ & sententiam expromere & consulem & inducere \\
\hline$(9)$ & ad meretricem & animum & inducere \\
\hline$(10)$ & in spem cogitationemque & animum & inducere \\
\hline$(11)$ & ut... consulam & animum & inducere \\
\hline$(12)$ & uxorem habere & animum & inducere \\
\hline$(2)$ & in ciuitatem & discordiam & inducere \\
\hline$(6)$ & in errorem & imperitos & inducere \\
\hline$(13)$ & in animum & ne... oderim & inducere \\
\hline$(14)$ & in animum & concedere & inducere \\
\hline
\end{tabular}


Estamos, por tanto, ante dos construcciones sintácticas en origen distintas: a partir del marco predicativo triargumental de inducere, surgen, por un lado, ejemplos como ut... consulam / uxorem habere animum inducere ('llevar el ánimo', 'animarse a' hacer algo), donde $u t+$ subj. (11) o el infinitivo prolativo (12) ocupan la casilla del tercer argumento de inducere, de forma similar a ejemplos como (5) o (6). En cambio, con ne oderim / concedere in animum inducere (lit. 'llevar al ánimo' a hacer algo), la casilla del OD es ocupada tanto por una completiva de $u t / n e+$ subj. (13), como por un infinitivo (14). Son, pues, dos perspectivas distintas, dos construcciones sintácticas alternantes, pero que acaban expresando contenidos similares.

Precisamente el sentido unitario de las dos colocaciones hace que su reanálisis sincrónico acabe siendo paralelo: en los ejemplos de (11) a (14) las completivas con $u t / n e+$ subj. o el infinitivo prolativo se entienden dependientes del conjunto del predicado analítico (animum inducere / in animum inducere) y de ahí que los traductores ${ }^{4}$ tiendan a trasladarlas de la misma forma bien mediante colocaciones paralelas en español ('tener la intención', 'tomar la decisión'), bien mediante verbos simples ('intentar', 'decidir').

5. Dos realizaciones semánticas distintas: como uerba decernendi o cogitandi

En los ejemplos comentados hasta ahora, tanto animum inducere como in animum inducere ('tomar una decisión, 'intentar', 'decidir', 'esforzarse por') se asemejan - $-\mathrm{y}$ así lo recogen las gramáticas latinas 5 - a uerba decernendi como statuo, decerno, constituo, paro, etc. y de ahí que se construyan, bien con $u t$ o ne + subj., como en (11) y (13), bien con un infinitivo prolativo, como en (12) y (14).

${ }^{4}$ Para no condicionar con mi propia traducción el análisis de determinados ejemplos, las traducciones están tomadas, sobre todo, de la Colección Biblioteca Clásica Gredos. En el caso de Plauto y Terencio he preferido las versiones de J. Ramón Bravo en Cátedra; para Cicerón, la de Alianza Editorial en el caso de Brut., Lael., y off., y para Quintiliano, la de A. Ortega, en Publicaciones de la Universidad Pontificia de Salamanca. Tan solo cuando dichas traducciones no eran transparentes sintácticamente para el análisis que se pretendía ilustrar, he ofrecido una traducción propia. En concreto, en los ejemplos (1), (20) y (21).

${ }^{5}$ Cf., por ejemplo, Kühner y Stegmann 1914, pp. 491-492; Ernout y Thomas 1953, p. 302; o Pinkster 2021, pp. 211-212. 
Pero, además (y este segundo valor es ignorado por las gramáticas latinas), cuando animum inducere o in animum inducere presentan una completiva de Acusativo con Infinitivo (AcI), como en (15), dichos predicados analíticos equivalen a un verbo de pensamiento (uerba cogitandi): «estar convenido de», «considerar», etc. son algunas de las paráfrasis en español de este segundo significado.

(15a) Etenim ille, quoniam semel induxit animum sibi licere quod uellet, fecisset nihilo minus me inuito («Sin duda él, pues de una vez se le ha metido en la cabeza que le está permitido cuanto le venga en gana, habría hecho exactamente lo mismo pese a mi oposición», Cic., Att. XIV 13.6).

(15b) eum esse quaestum in animum induxi maxumum, / quam maxume seruire uostris commodis («siempre consideré que mi mejor negocio era servir lo mejor posible a vuestros intereses», Ter., Hec. 50-51).

Estas dos realizaciones semánticas son reflejo en último término de la propia polisemia del sustantivo animus, que, como bien recogen los diccionarios ${ }^{6}$, presenta, por un lado, el significado de «mente, pensamiento» y, por otro, el de «intención, deseo, propósito», dos significados que se actualizan también en otras CVS. Así, por ejemplo, animum aduertere se realiza siempre como un predicado de pensamiento («darse cuenta, advertir»), y se construye con una completiva de AcI, como en (16), mientras que las CVS in animo habere (17a) e in animo esse (17b) equivalen por lo general a un verbo de intención o esfuerzo («tener la intención, intentar»), y de ahí que presenten de forma constante un infinitivo prolativo:

${ }^{6}$ Así, por ejemplo, Lewis y Short 1879, s. u., distinguen dos valores fundamentales de animus: «A. The general power of perception and thought, the reason, intellect, mind (syn.: mens, ratio, ingenium), o voṽ » y «B. The power of feeling, the sensibility, the heart, the feelings, affections, inclinations, disposition, passions (syn.: sensus, adfectus, pectus, cor), $\dot{o}$ $\theta v \mu o ́ c »$. Gaffiot 2016, s. u., por su parte, señala que animus se puede entender como «siège de la pensée» o como «siège du désir et de la volonté..., du sentiment et des passions», una distinción muy similar a la de Glare 1968, s. u., en el Oxford Latin Dictionary. En fin, el ThLL distingue claramente entre «II. cogitandi facultas» y «III. concupiscendi facultas, voluntas». 
(16) animum aduerti enim hoc uos magnos oratores facere non numquam («pues me he dado cuenta de que vosotros, grandes oradores, lo hacéis así alguna vez», Cic., fam. XII 18.1).

(17a) Is nuntiat L. Domitium ... habuisse in animo proficisci Corfinio a. $d$. $V I d$. Febr. («Me anuncia que Lucio Domicio ... tiene intención de abandonar Corfinio el 9 de febrero», Cic., Att. VIII 11a.1).

(17b) Mihi autem erat in animo iam, ut antea ad te scripsi, ire in Epirum («Mi intención ahora es, como ya te he escrito, ir a Epiro», Cic., Att. III 21.1).

Esta polisemia es también común (y, por tanto, la doble construcción sintáctica) a verbos de contenido similar a las dos CVS como censeo, decerno o statuo. Al igual que en español con un verbo como pensar caben las dos realizaciones (pienso estudiar todos los días, es decir, tengo la intención de estudiar vs. pienso que el estudio es necesario), en latín «plusiers des verbes ... avaient en même temps un sens déclaratif ..., tandis que la proposition avec ut énonçait un ordre ou une intention» (cf. Ernout y Thomas 1953, p. 303); o, dicho de otro modo, «las oraciones de $u t$ y las construcciones de infinitivo prolativo son sinónimas y están en oposición a la construcción de AcI» ${ }^{7}$ (Pinkster 1995, p. 164). Compárense, por ejemplo, (18), donde statuo se construye como uerbum cogitandi con AcI, y (19), en cambio, con $u t+$ subj. (19a) o un infinitivo prolativo (19b), ya que se realiza como uerbum decernendi:

(18) non statuebas tibi non solum de tuis, sed etiam de illorum factis rationem esse reddendam? ("¿no pensabas que tenías que dar cuenta cuenta no solo de tus propios actos, sino de los de ellos?», Cic., Verr. II 2.29).

(19a) Statuunt ut decem milia hominum ... submittantur («Deciden que se envíen ... diez mil hombres», Caes., Gall. VII 21.2).

(19b) impetum facere in arcem statuunt («deciden atacar la ciudadela», Liu. V 43.2).

${ }^{7}$ Esta distinción y distribución sintáctica (AcI como uerba cogitandi vs. $u t+$ subj. o infinitivo prolativo como uerba decernendi) se mantiene, por ejemplo, en la entrada de animus del Thesaurus, en la que se agrupan los ejemplos de animum / in animun inducere, en dos apartados distintos según animus exprese «II. cogitandi facultas» o «III. concupiscendi facultas, uoluntas». Pero no siempre: se considera cognitivo (es decir, se cita en $\S$ II), un ejemplo como Si ego te noui, animum inducam, ut tu noueris («Puesto que te conozco a ti, haré que también tú me conozcas a mí», Plaut., Epid. 550), donde la completiva de $u t+$ subj. impide precisamente una interpretación cognitiva (*«pensaré que tú me conoces»). 
Con estas consideraciones previas, el objetivo de las páginas que siguen es mostrar, por un lado, la evolución diacrónica de estas dos colocaciones verbo-nominales y su frecuencia de empleo ( $§$ II), y, por otro, analizar sus semejanzas y diferencias (§ III). Además, a la hora de explicar su origen, evolución diacrónica y realización como uerba cogitandi o decernendi, se muestra relevante su relación con otras CVS como animum aduertere, in animo habere e in animo esse, con las que guardan, como veremos (§ IV), no pocos paralelismos.

\section{LOS DATOS}

\section{Evolución diacrónica de las dos construcciones}

Para entender las convergencias y divergencias entre las dos construcciones, una primera cuestión fundamental tiene que ver con su evolución diacrónica y frecuencia de empleo. Los datos que se presentan en el Cuadro (2) proceden de una búsqueda completa en el corpus del Packard Humanities Institute (PHI), con el programa Diogenes, del verbo inducere desde el s. II a. C. hasta Tácito $^{8}$, es decir casi cuatro siglos de literatura latina, al que, además de los ejemplos de las inscripciones ${ }^{9}$, he añadido un corpus suplementario y significativo de latín tardío ${ }^{10}$.

En el Cuadro 2 recojo, desglosada por autores, la frecuencia (entre paréntesis el $\mathrm{n}^{\mathrm{o}}$ de ejemplos, cuando es más de uno) de cada construcción en latín arcaico, clásico, posclásico y tardío.

${ }^{8}$ Los datos de Cuadro 2 han sido confirmados, de todos modos, en una búsqueda paralela en la base de datos Brepolis.

${ }^{9}$ Para ello he realizado una búsqueda en las inscripciones recogidas en el corpus de Epigraphik-Datenbank Clauss-Slaby, <http://www.manfredclauss.de/es/index.html> (29/10/2020). Para los ejemplos, cf. infra, nota 17.

${ }^{10}$ En concreto, Ambrosio, Amiano Marcelino, Agustín, Arnobio, Aurelio Víctor, Diomedes, Eutropio, Historia Augusta, Itinerarium Aetheriae, Jerónimo, Lactancio, Minucio Félix, Paladio, Servio, Sulpicio Severo, Tertuliano y la Vulgata. Para ello, se ha completado la búsqueda en la base de datos de PHI (para la Historia Augusta y la Vulgata) con una búsqueda propia del resto de autores y obras a partir fundamentalmente del repositorio de Corpus Corporum, <http://mlat.uzh.ch/MLS/> (29/10/2020). 
Cuadro 2: frecuencia de animum inducere e in animum inducere:

\begin{tabular}{|l|l|l|l|}
\hline & \multicolumn{1}{|c|}{ animum inducere } & \multicolumn{1}{|c|}{ in animum inducere } & Total \\
\hline Latín arcaico & $\begin{array}{l}\text { 26 ejs.: Cato; Lucil. (2); } \\
\text { Plaut. (10), Scip. min.; } \\
\text { Ter. (9). inscr. (3) }\end{array}$ & 33 ejs. \\
\hline Latín clásico & 11 ejs.: Cic. (10), Hor. & 21 ejs.: Cic.; Q. Cic.; Sall.; Liv. (18), Ter. (5). & 32 ejs. \\
\hline $\begin{array}{l}\text { Latín posclá- } \\
\text { sico }\end{array}$ & 2 ejs.: Apul., Fronto. & $\begin{array}{l}10 \text { ejs.: Val. Max. (3), Quint., Apul., } \\
\text { Fronto, Suet., Plin., Gell. (2). }\end{array}$ & 12 ejs. \\
\hline Latín tardío & 0 ejs. & $\begin{array}{l}22 \text { ejs.: Ambr., (2), Arnob., Aug. (7), } \\
\text { Diom. (2), Historia Augusta, Lact., } \\
\text { Min. Fel., Pallad. (5), Tert. (2) }\end{array}$ & 22 ejs. \\
\hline
\end{tabular}

La comparación, en términos absolutos ( $\mathrm{n}^{\mathrm{o}}$ de ejemplos), de cada construcción muestra una clara evolución diacrónica: la CVS animum inducere es la más frecuente con diferencia en latín arcaico (26 ejs.), pero su empleo decrece progresivamente en latín clásico (11 ejs.) y posclásico (2 ejs.). Paralelamente, in animum inducere, ya presente en latín arcaico (7 ejs.) y minoritaria aún en el latín preagusteo ( 3 ejs.), se acaba convirtiendo en la construcción por excelencia en Livio (18 ejs.) y en latín posclásico, siendo ya la única documentada en el corpus analizado del latín tardío.

Esta evolución diacrónica se hace más visible en el Gráfico 1: mientras que en latín arcaico más de tres cuartas partes de los ejemplos pertenecen a la construcción animum inducere, en latín clásico la situación se invierte: animum inducere representa ya solo un tercio de los ejemplos, para convertirse en latín posclásico en una construcción marginal. En latín tardío (al menos en el corpus analizado) ${ }^{11}$ solo se documenta ya in animum inducere.

${ }^{11}$ Pero no se pueden excluir. Agradezco en este sentido a un informante anónimo la referencia a dos ejemplos puntuales, en el s. V d. C., de animum inducere: Macr., Sat. 14,7 (non poteram animum inducere) y Leo M., haer. 55, 1181D (animum ... inducere possunt). 


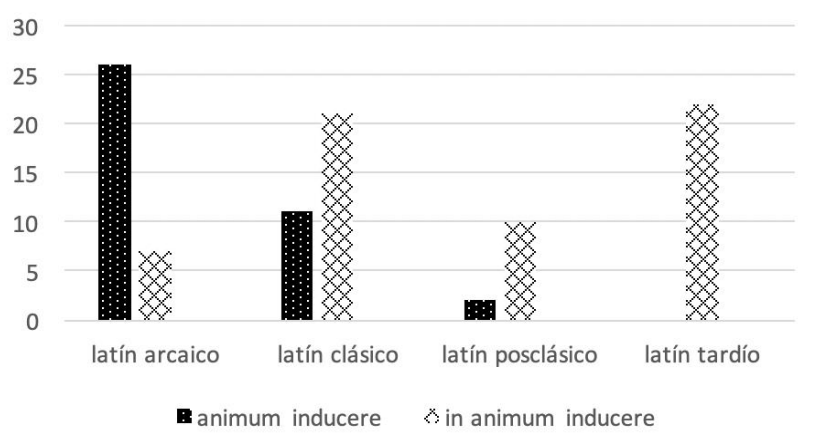

Gráfico 1: frecuencia de las dos colocaciones por periodos históricos

\section{Equivalencia entre las dos CVS: problemas de critica textual}

Tanto los ejemplos paralelos de las dos CVS, ya comentados, de (11)-(15), como los datos de frecuencia y evolución diacrónica invitan a pensar, de entrada, que se trata efectivamente de dos construcciones equivalentes: estaríamos, de ser así, ante un ejemplo más de la renovación diacrónica de las colocaciones verbo-nominales en latín. En este caso, la renovación no supondría variar el verbo soporte como in memoria habere vs. memoria tenere (Baños 2018, p. 31) o ludos facere vs. ludos edere (Baños 2012, pp. 40-41; López Martín 2019), sino simplemente la construcción sintáctica: animum inducere vs. in animum inducere sería una alternancia sintáctica similar a odium vs. odio (dat.) habere, odio vs. in odio esse, etc. (Baños y Jiménez 2017; Tur 2019, pp. 125-198).

Se trata, por supuesto, de un proceso progresivo, como muestra claramente, por un lado, el mantenimiento de las dos construcciones hasta el latín posclásico $\mathrm{y}$, por otro, la existencia de diferencias notables entre autores dentro de un mismo período histórico. Así, en latín clásico, son más que llamativas las diferencias entre Cicerón y Livio: mientras que en el orador animum inducere es la colocación casi exclusiva (10 de los 11 ejemplos), Livio emplea ya únicamente in animum inducere (18 ejemplos).

Sea como fuere, la simple constatación de esta evolución diacrónica invita a pensar en una equivalencia efectiva entre ambas CVS. En otras palabras, si in animum inducere acaba desplazando a animum inducere es porque las 
diferencias entre las dos colocaciones, de existir, se han desdibujado progresivamente hasta entenderse ambas CVS como equivalentes.

Esta equivalencia ayuda a entender algunas dudas y problemas de crítica textual. Así, por ejemplo ${ }^{12}$, Cicerón presenta dos pasajes en sus discursos en los que los editores no se ponen de acuerdo a la hora de decidirse por animum inducere o in animum inducere como mejor lectura:

(20a) Nam Habitus usque ad illius iudici tempus nullum testamentum umquam fecerat; neque enim legare quicquam eius modi matri poterat in animum inducere neque testamento nomen omnino praetermittere parentis («Pues Hábito, hasta el momento de aquel juicio, no había hecho nunca testamento. $Y$ es que ni podía pensar en dejar nada a una madre como aquella ni omitir por completo en el testamento el nombre de su progenitora», Cic., Cluent. 45).

(20b) adeo immemor rerum a me gestarum esse uideor ut, cum consul bellum gesserim cum coniuratis, nunc eorum ducem seruare cupiam et animum inducam ... eiusdem nunc causam uitamque defendere? («ios parece que me olvido de mis gestas hasta tal punto de desear ahora - habiendo hecho como hice en mi consulado la guerra contra los conjurados - salvar a uno de sus cabecillas e intentar ... defender ahora la causa y la vida de esa misma persona?», Cic., Sulla 83).

He reproducido en ambos casos el texto de las ediciones oxonienses de Clark (1905, 1911), por ser las empleadas en el corpus de PHI. Clark en (20a) ignora la lectura concordante (animum inducere) de los mejores manuscritos del Pro Cluentio porque da más valor al testimonio indirecto (in animum inducere) del gramático del s. IV d. C. Arusiano Mesio (Keil 1878, p. 479); a su vez, en (20b), frente a la lectura unánime de la tradición manuscrita del Pro Sulla (in animum inducam), opta por animum inducam, para lo que remite, como apoyo, a la edición del humanista Franciscus Sylvius (1531).

Sin entrar en la discusión de estos ejemplos puntuales ${ }^{13}$ —las ediciones teubnerianas de Früchtel (1931) y Kasten (1949), respectivamente, presentan justo la lectura contraria a Clark en (20a) y (20b)_-, estas vacilaciones y los

12 Aunque con una controversia menor, también Plauto (Cist. 633; Mil. 1269) y Terencio (Ad. 597; Andr. 752; Hec. 50, 264) presentan ejemplos con problemas de crítica textual.

${ }^{13}$ A mi juicio (cf. Baños 2021b), no hay razones lingüísticas ni filológicas para desechar la lectura concordante de la totalidad (Sulla 83) o de los mejores manuscritos (Cluent. 45). 
argumentos esgrimidos por los editores para justificar una u otra lectura son una prueba más de hasta qué punto ambas CVS se consideraban equivalentes.

\section{ANIMVM INDVCERE VS. IN ANIMVM INDVCERE: DIFERENCIAS Y CONVERGENCIAS}

Cabe preguntarse, de todos modos, si existen diferencias de distribución sintáctica o de contenido entre las dos CVS. Para ello, voy a analizar con algo más de detalle el empleo de animum inducere e in animum inducere en Plauto, Terencio, Cicerón y Livio, que son los cuatro autores que documentan más ejemplos, tal como recogían los datos del Cuadro 2. Además, los tres primeros autores emplean indistintamente las dos contrucciones, una situación ideal para establecer la comparación, por contraste, entre una y otra.

\section{Fijación formal y orden de palabras}

Un primer factor comparativo tiene que ver con el grado de fijación formal y orden de palabras entre los dos términos (sustantivo y verbo, base y colocativo) que configuran toda CVS. Al fin y al cabo, el sentido unitario de las CVS y su grado de gramaticalización se reflejan también de manera icónica en su cohesión formal, es decir, en la unión casi indisoluble entre sustantivo y verbo.

Desde esta perspectiva, en el caso de la CVS animum inducere, la contigüidad entre sustantivo y verbo es casi absoluta ${ }^{14}$. Solo en tres pasajes esa contigüidad se ve mínimamente mitigada por la interposición de un pronombre (animum ego inducam, Plaut., Cist. 633), un infinitivo (animum adsentari induxeris, Ter., Eun. 490) o un verbo modal (animum poteris inducere, Cic., diu. 1,22). Por otra parte, y sobre todo, el orden de palabras casi constante es sustantivo-verbo ${ }^{15}$.

En el caso de in animum inducere, en cambio, aunque todos los ejemplos presentan contigüidad entre verbo y sintagma preposicional, hay una mayor

\footnotetext{
En todo caso, se adopten las lecturas de Clark o las de los manuscritos, no varían las cifras globales de frecuencia de ambas CVS en Cicerón recogidas en el Cuadro 2 ni su distribución.

${ }^{14}$ A diferencia de ejemplos no colocativos como (9): Nunc animum rursum ad meretricem induxti tuom (Ter., Hec. 689).

${ }^{15}$ En concreto: Plaut., Bacch. 1191, Asin. 832; Cic., Att. XIV 13.6, Tusc. 5.30.
} 
flexibilidad en el orden de palabras. Es verdad que predomina la anteposición en el conjunto de los cuatro autores (15 ejs. de in animum inducere $)^{16}$, pero la posposición también es frecuente (11 ejs. de inducere in animum): Livio, por ejemplo, emplea indistintamente el orden antepuesto ( 8 ejs.) y pospuesto (10 ejs.).

En definitiva, en Plauto, Terencio, Cicerón y Livio, el grado de fijación formal (y, por tanto, el grado de gramaticalización) es menor en el caso de in animum inducere, tal como se refleja, de manera comparativa, en el Gráfico 2:

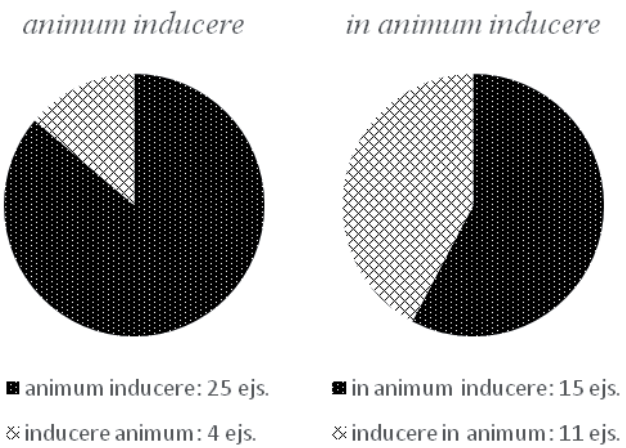

Gráfico 2: orden de palabras en animum / in animum inducere (Plaut. Ter. Cic. Liv.)

\section{Complementación pronominal e incorporación sintáctica}

Un segundo factor comparativo tiene que ver con el tipo de complementación (pronominal $\mathrm{u}$ oracional) que presentan animum inducere e in animum inducere, notablemente similar en Plauto, Terencio, Cicerón o Livio. Y es que las dos CVS presentan de manera casi constante una oración completiva (§ III.3), salvo en ejemplos puntuales de acusativos pronominales (demostrativos o relativos) que, por su interés, voy a comentar brevemente.

Precisamente por la regularidad con que estos predicados analíticos presentan una oración completiva, nada tiene de extraño (Bodelot 1995)

${ }_{16}$ Pero en cuatro de esos casos (Plaut., Rud. 22; Ter., Ad. 597, Hec. 292, Heaut. 1028) in animum lleva un adjetivo posesivo (meum, tuom, suom) concertado que se posponen al verbo, como en (21a). 
que un pronombre neutro remita (catafóricamente) a dicha completiva, como ocurre en (21):

(21a) hoc scelesti in animum inducunt suom, / Iouem se placare posse donis («esto es lo que esos malvados se imaginan: que se puede aplacar a Júpiter con ofrendas y víctimas», Plaut., Rud. 22-23).

(21b) obsecro, mi gnate, ne istuc in animum inducas tuom / alienum esse te («Te lo suplico, hijo mío: no admitas la idea esa de que tú eres un extraño», Ter., Heaut. 1028).

Por otro lado, se documentan también estructuras catafóricas, como (22), en la que el contenido de la oración de relativo se expresa a posteriori en estilo directo, mediante una oración independiente:

(22) Inducite in animum quod non induxerunt patres auique uestri ... expectate ... matres coniugesque crinibus passis obuiae ab urbe ueniant («Tomad una decisión que no tomaron vuestros padres y abuelos ...: esperad ... a que os salgan al encuentro desde Roma vuestras madres y esposas, con los cabellos sueltos», Liu. VII 40.11).

En los tres ejemplos comentados hasta ahora estamos ante estructuras catafóricas, ya que la completiva aparece en aposición a un pronombre (21) o su contenido se expresa a posteriori como una oración independiente (22).

Los ejemplos de (23) y (24) ilustran en cambio estructuras anafóricas. En efecto, en el ejemplo plautino de (23), con istuc Ergásilo recoge y rechaza la reflexión previa de Hegión, quien había manifestado su sorpresa por que un extraño como Ergásilo sintiera tanto dolor por la desgracia de su hijo (alienus quom eius incommodum tam aegre feras): istuc, anafórico, complementa tanto a dixis como a animum induxis. El pasaje de (24) es en gran medida paralelo a (23), solo que es el relativo quod el que retoma y remite a la idea expresada en el contexto precedente (sperasse se aliquid).

(23) aha Hegio, / numquam istuc dixis neque animum induxis tuom; / tibi ille unicust, mi etiam unico magis unicus («iAy Hegión, nunca digas eso, ni lo pienses siquiera! Para ti es tu único hijo, para mí es más único que lo único», Plaut., Capt. 149)

(24) sed in ipsa decessione significauit sperasse se aliquid et id quod animum induxerat paulisper non tenuit («Pero en el momento mismo de la partida me dio a entender que había concebido alguna esperanza; 
mas eso que había tenido por un breve tiempo en la cabeza, no le duró mucho», Cic., Att. VII 3.8).

Pero, además de su carácter anafórico, los ejemplos de (23) y (24), ambos con animum inducere, son relevantes por otra razón. En efecto, (24) es citado por Hofmann y Szantyr (1965, p. 44) como un ejemplo de incorporación sintáctica, es decir, «where the combination and fusion of the object and its governing verb itself governs an argument, viz. animum aduerto or animaduerto ('to pay attention') ${ }^{17}$. En otras palabras, en (24) el acusativo pronominal (quod) funcionaría ya como OD del predicado complejo animum-inducere, de manera similar a los acusativos pronominales (25a) o nominales dependientes de otras CVS como animum-aduertere (25) o ludos-facere (26):

(25a) id animum aduertito ... («Tenedlo presente ... », Cato, agr. I 2.2).

(25b) nunc adeo hanc edictionem nisi animum aduortetis omnes ... («Ahora, si a mi bando no le prestáis todos atención ... », Plaut., Pseud. 143).

(26) Exploratorem hunc faciamus ludos suppositicium adeo donicum ipsus sese ludos fieri senserit («Tomémosle el pelo a este falso mensajero hasta que se dé cuenta de que se lo estamos tomando», Plaut., Pseud. 1167-1168).

De aceptarse el análisis de istuc en (23) y quod en (24) como ejemplos de incorporación sintáctica ${ }^{18}$, análisis que habría que hacer extensible a otros casos de animum inducere ${ }^{19}$, dichos ejemplos mostrarían en último término

17 Pinkster 2015, p. 173.

${ }^{18}$ El grado de gramaticalización no es, de todos modos, el mismo en animum inducere y en ludos facere ('gastar bromas' 'burlarse' de alguien): en el caso de ludos facere el sustantivo predicativo (ludos) en pasiva se mantiene en acusativo (Baños 2012, pp. 44-47) y es el complemento de persona el que se codifica como sujeto sintáctico, tal como muestra el ejemplo (26). En cambio, en la pasiva de animum inducere, animus sigue siendo el sujeto sintáctico: animus induci potest, / eum esse ciuem et fidelem et bonum («de ese se puede creer que es un ciudadano bueno y honesto», Plaut., Persa 66-67).

19 Otro ejemplo similar a (24), pero «unklar» (Hofmann y Szantyr 1965, p. 44), podría ser aut quod animum induxit semel et uti<l>e omnino putat («o lo que él puso una vez en la cabeza y piensa que es enteramente útil», Lucil., fr. 27,695). Pinkster (2015, p. 174) cita también ea nos animum nostrum / non indoucebamus ita facta esse («nosotros no creíamos que esto - ea- había sucedido así», CIL I², 586.3-4, Tívoli ca. 100 a. C.). Pero, tal como he intentado reflejar en la traducción, ea, más que el OD de animum inducebamus, es el sujeto 
que animum inducere no solo es de las dos CVS la más frecuente en latín arcaico sino que además ha alcanzado ya, como animum aduertere (Fruyt 1990, Fugier 1994) o ludos facere (Baños 2012), el grado máximo de gramaticalización, al sentirse como un predicado único y «retransitivizarse».

\section{Complementación oracional}

Más allá de estos ejemplos con formas pronominales neutras en acusativo, animum inducere e in animum inducere presentan en Plauto, Terencio, Cicerón y Livio, de forma constante, una completiva, que puede expresarse de tres formas distintas: (i) mediante una subordinada conjuncional en subjuntivo, sobre todo con ut/ne + subj., y excepcionalmente con quin/quominus + subj., (ii) mediante un infinitivo prolativo, o (iii) mediante una construcción de Acusativo con Infinitivo (AcI).

A continuación, se ofrecen ejemplos de los tres tipos de subordinadas, tanto con animum inducere (ejemplos tipo a) como con in animum inducere (ejemplos tipo b). Los dos únicos ejemplos de quin (31) o quominus (32)+ subj. se documentan con in animum inducere a partir de Livio y siempre con la oración principal negada:

(27a) ... explicare omnia uitia ac peccata fili quibus incensus parens potuerit animum inducere ut naturam ipsam uinceret («... exponer detalladamente todos los vicios y faltas del hijo por los que el padre, irritado, pudo determinarse a vencer su propia naturaleza», Cic., Rosc. Am. 53).

(27b) Sed quoniam uos regno impotenti finem ut imponatis non inducitis in animum ... («Pero ya que vosotros no os decidís a poner límites a vuestro prepotente dominio ... », Liu. VIII 5.4).

(28a) Quamquam ego istanc amo, / possum equidem inducere animum, ne aegre patiar quia tecum accubat («Aunque yo la amo, trataré de soportar con resignación verla recostada a tu lado», Plaut., Asin. 831-832).

de la completiva de AcI (ea...ita facta esse). En la misma inscripción se vuelve a repetir animum inducere otras dos veces con el mismo sentido («pensar, considerar»), y de nuevo con una completiva de AcI: animum nostrum indoucimus... de eeis rebus af uobeis peccatum non esse (CIL I $\left.\mathrm{I}^{2}, 586.10-11\right)$; animum uostrum indoucere oportet item uos populo Romano purgatos fore CIL I' $\left.\mathrm{I}^{2}, 586.13-14\right)$. 
(28b) Induxi in animum, ne oderim item ut alias, quando orasti («He tomado la decisión de no despreciarla como a las demás, ya que me lo has pedido», Plaut., Mil. 1269).

(29a) nam qui huic animum adsentari induxeris, / e flamma petere te cibum posse arbitror («pues si has podido decidirte a adular a semejante personaje, creo que serías capaz de robar comida en una pira», Ter., Eun. 490-491).

(29b) inducetis in animum negare Eumenis cupiditati, quod iustissimae irae uestrae negastis («os decidiréis a negar a la ambición de Éumenes lo que negasteis a vuestra justísima ira», Liu. XXXVII 54.27).

(30a) quae dicis omnia esse ut dicis animum induco ("estoy convencido de que todo lo que dices es como dices», Ter., Hec. 264).

(30b) eum esse quaestum in animum induxi maximum / quam maxume seruire uostris commodis («siempre consideré que mi mayor negocio era servir lo mejor posible a vuestros intereses», Ter., Hec. 50-51).

(31) ... non potuisse se tamen inducere in animum quin, quem agrum miles pro parte uirili manu cepisset, eum senex ... uindicaret. («... no ha podido avenirse a no reivindicar de viejo ... un territorio que él contribuyó como soldado a conquistar por las armas», Liu. III 71.8).

(32) Sed non sustinui inducere in animum, quominus illi eodem die facturum me indicarem («Sin embargo, no me pude contener de hablarle ese mismo día del proyecto que iba a realizar», Plin., epist. IX 13.6).

Cabe preguntarse si existe alguna diferencia significativa entre las dos CVS en cuanto al tipo de complementación oracional se refiere. Para ello, en el Cuadro 3 se resume la frecuencia global de cada tipo de completivas en los cuatro autores de referencia:

Cuadro 3: tipos de completivas en dependencia de animum / in animum inducere

\begin{tabular}{|l|c|c|c|c|c|c|}
\hline \multirow{2}{*}{} & \multicolumn{3}{|c|}{ animum inducere } & \multicolumn{3}{c|}{ in animum inducere } \\
\cline { 2 - 7 } & $\begin{array}{c}\text { ut/ne } \\
+ \text { subj. }\end{array}$ & $\begin{array}{c}\text { infinitivo } \\
\text { prolativo }\end{array}$ & AcI & $\begin{array}{c}\text { ut/ne/quin } \\
\text { subj. }\end{array}$ & $\begin{array}{c}\text { infinitivo } \\
\text { prolativo }\end{array}$ & AcI \\
\hline Plauto & 5 & 2 & 2 & 1 & - & 1 \\
\hline Terencio & - & 3 & 6 & - & 1 & 4 \\
\hline Cicerón & 2 & 5 & 2 & - & 1 & - \\
\hline Livio & - & - & - & 7 & 8 & 2 \\
\hline Total & 7 & 10 & 10 & 8 & 10 & 7 \\
\hline
\end{tabular}


Como se ve, más allá de los ejemplos puntuales de quin + subj. (31) o quonimus + subj. (32), en términos globales el empleo de cada tipo de subordinada no parece estar asociado a una CVS determinada. La distribución, en cifras absolutas, es prácticamente idéntica, lo que abunda una vez más en la idea de que las dos CVS se acaban considerando equivalentes ${ }^{20}$. Tampoco de la comparación, en cada par de ejemplos, entre animum inducere e in animum inducere se observan diferencias de sentido apreciables, lo que explica que las traducciones sean similares para una u otra CVS cuando presentan el mismo tipo de completiva.

\section{Tipos semánticos}

Como ya hemos adelantado ( $§$ I.5), no todas las completivas en dependencia de estas CVS son de la misma naturaleza semántica: en los ejemplos con un infinitivo prolativo (29) o con una completiva en subjuntivo introducida por ut (27), ne (28), quin (31) o quominus (32), tanto animum inducere como in animum inducere se realizan como verbos de intención o esfuerzo (uerba decernendi), y así lo reflejan los traductores que vierten estos predicados por 'decidirse a', 'determinarse a', 'tratar de', 'tomar la decisión de', etc.

En cambio, cuando animum inducere o in animum inducere presentan una completiva de AcI, como en (30), estos predicados analíticos equivalen a un verbo de pensamiento (uerba cogitandi): 'estar convenido de', 'imaginar', 'considerar', 'meterse en la cabeza la idea de que', etc. son paráfrasis de este otro significado.

Llegados a este punto, cabe preguntarse si hay alguna diferencia, desde un punto de vista sincrónico o diacrónico, entre animum inducere e in animum inducere según se realicen como verbos de intención o como verbos de pensamiento, con independencia ya del tipo de complementación (pronominal $\mathrm{u}$ oracional) que presenten.

${ }^{20}$ Nuestros datos matizan considerablemente la afirmación de Kühner y Stegmann 1914, pp. 491-492, de que in animum inducere es «menos frecuente» («seltener») que animum inducere con un infinitivo prolativo. Por un lado, en los cuatro autores analizados los datos globales son similares (10 ejemplos con cada CVS). Por otro, desde un punto de vista diacrónico, a partir de época clásica, in animum inducere presenta un infinitivo prolativo con mucha más frecuencia que animum inducere. 
Para ello, en el Cuadro 4 se cuantifican, agrupados por períodos históricos y tipos semánticos, los ejemplos de las dos CVS recogidos en el Cuadro 2 de $\S$ II. $1^{21}$ :

Cuadro 4: empleo de animum / in animum inducere como verbos de intención o de pensamiento

\begin{tabular}{|c|c|c|c|c|c|}
\hline & \multicolumn{2}{|c|}{ animum inducere } & \multicolumn{2}{|c|}{ in animum inducere } & Total \\
\hline & v. intención & v. pensamiento & v. intención & v. pensamiento & \\
\hline latín arcaico & 10 & 16 & 2 & 5 & 33 \\
\hline latín clásico & 8 & 2 & 19 & 3 & 32 \\
\hline $\begin{array}{l}\text { latín posclá- } \\
\text { sico }\end{array}$ & 1 & 1 & 7 & 3 & 12 \\
\hline latín tardío & - & - & 16 & 6 & 22 \\
\hline total & 19 & 19 & 44 & 17 & 100 \\
\hline
\end{tabular}

En el caso de animum inducere, aunque en términos absolutos esta CVS se emplea por igual como verbo de pensamiento y de intención, desde un punto de vistra diacrónico es evidente que su realización como verbo de pensamiento se circunscribe casi exclusivamente al latín arcaico, donde es además el valor más frecuente, lo que invita a pensar que tal vez se trate de su valor originario.

En el caso de in animum inducere, en cambio, hay una clara preferencia por su realización como verbo de intención en términos absolutos (44 ejs. frente a 17 como verbo de pensamiento) y en todos los periodos históricos, salvo en latín arcaico.

Para ofrecer una perspectiva complementaria, en el Gráfico 3, se cuantifican de manera comparada, en cada período histórico, los dos tipos semánticos, pero con independencia de si el predicado principal es ya animum inducere o animum inducere. El gráfico muestra más claramente que el empleo de las dos CVS como verbos de pensamiento es un rasgo propio del latín

${ }^{21}$ En el Cuadro 4, por tanto, he tenido en cuenta no solo los ejemplos de los cuatro autores de referencia, sino el conjunto del corpus analizado en el Cuadro 2, incluidas inscripciones y autores tardíos. 
$\operatorname{arcaico}^{22}$, mientras que a partir de época clásica su realización fundamental es como verbos de intención:

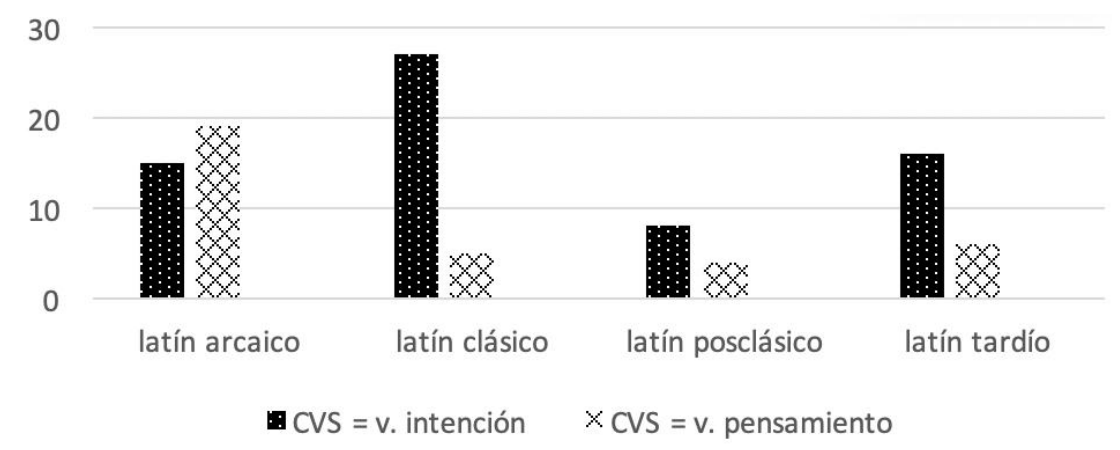

Gráfico 3: realización semántica de las dos colocaciones por periodos históricos

IV. UNA HIPÓTESIS DIACRÓNICA: LA RELACIÓN CON ANIMUM ADVERTERE, IN ANIMO HABERE / ESSE

A la vista de todos estos datos, cabe preguntarse cuál es el valor originario (si es que es posible determinarlo) de cada CVS, porque resulta difícil imaginar que desde el primer momento tanto animum inducere como in animum inducere gramaticalizaran por igual las dos realizaciones semánticas.

Pues bien, para responder a esta pregunta y entender mejor el origen de estas CVS y su evolución diacrónica, me parece iluminador ponerlas en relación con otras CVS de uso frecuente en las que también interviene el sustantivo animus: animum aduertere (§ IV.1) e in animo habere / in animo esse (IV.2).

${ }^{22}$ Hay, con todo, diferencias notables entre autores y tipos de textos. Así, por ejemplo, en Plauto es mayoritario el empleo como verbos de esfuerzo ( 8 ejs.) frente a 4 como verbo de pensamiento, justo la situación inversa a Terencio (4 y 10 ejs., respectivamente). En el caso de las inscripciones, en los tres ejemplos animum inducere se realiza como verbo de pensamiento (supra, nota 17). 
1. Relación de animum inducere con animum aduertere

E1 verbo ad-uerto ('dirigir', 'encaminar', 'volver hacia') presenta un significado originario muy próximo a in-duco: los dos son verbos de movimiento transitivos y preverbiados y los dos presentan en origen un marco triargumental (sujeto / OD concreto / dirección), del que derivan, por un proceso metafórico y de abstracción, los empleos colocativos.

En el caso de aduerto, la CVS animum aduertere ('prestar atención a', 'darse cuenta de' $)^{23}$ se convierte casi en el único empleo real del verbo aduerto en Plauto, Terencio, Cicerón o César, es decir, aduerto es en latín arcaico y clásico fundamentalmente un verbo soporte. De la pronta gramaticalización de esta CVS son buena muestra, por un lado, ejemplos de incorporación sintáctica (Fugier 1994, pp. 77-83) como los de (25), ya comentados, con un nuevo OD nominal (hanc edictionem) o pronominal (id), un paso previo a la «univerbación» de esta colocación verbo-nominal, convertida pronto en un verbo compuesto: animaduertere.

Aunque en época clásica coexisten ambas posibilidades, en el caso de César y el corpus cesariano, por ejemplo, la forma sintética animaduertere se emplea ya con mucha más frecuencia que la forma analítica animum aduertere (Baños 2012, pp. 48-49). Pero lo que me interesa destacar ahora es que con ad-uertere, que presenta el mismo marco predicativo que in-ducere, la CVS animum aduertere se realiza únicamente como verbo de pensamiento ('darse cuenta'), o, dicho de otro modo, no presenta empleos como verbo de intención, con $u t+$ subj. o un infinitivo prolativo. En efecto, cuando la CVS presenta una completiva, esta se expresa regularmente ${ }^{24}$ mediante un AcI:

(33a) postquam id tanto opere uos uelle animum aduorteram ... («al darme cuenta de que teníais tanto interés en este asunto ... », Ter., Phor. 909).

(33b) animum aduerti enim hoc uos magnos oratores facere non numquam («me he dado cuenta de que vosostros, grandes oradores, lo hacéis así alguna vez», Cic., fam. XII 18.1).

${ }^{23}$ Animum attendere es otra CVS con el mismo sentido ('prestar atención), documentada desde latín arcaico (Lucil. 27.693; Ter., And. 8, Eun. 44, Phorm. 24; 868; Cic., off. 3.35, Verr. II 1.28; Nep., Alc. 5.2; Quint., decl. 339.12; Gell. II 23.11; X 11.6) aunque mucho menos frecuente que animum aduertere. De nuevo, un verbo de movimiento (ad-tendo) transitivo preverbiado, con un marco predicativo triargumental.

${ }^{24} \mathrm{O}$ mediante una interrogativa indirecta: cf., por ejemplo, Plaut., Trin. 842a. 
A mi juicio, la pronta gramaticalización de animum aduertere, su frecuencia de empleo ${ }^{25} \mathrm{y}$ el hecho de que presente solo AcI como forma de expresión completiva, bien pudieron influir en el desarrollo de animum inducere, CVS que presenta la misma estructura sintáctica (animum es en ambos casos OD del verbo soporte) y ejemplos también de incorporación sintáctica (§ III.2). De ser así, esta influencia ayudaría a explicar la frecuencia misma de animum inducere en latín arcaico (§ II.1), muy superior a la de in animun inducere; por otra parte, la analogía con animum aduertere favoreció la realización misma de animum inducere como verbo de pensamiento, una realización que parece haber sido el sentido originario o más antiguo de esta CVS, a la luz de los datos del Cuadro (4) y del testimonio mismo de las inscripciones arcaicas $^{26}$, que por su carácter conservador (se trata de textos normativos) tienden a mantener las construcciones más antiguas (Spevak 2018, p. 207).

\section{Relación de in animum inducere con in animo habere, in animo esse}

Si animum aduertere influyó, como creo, en el desarrollo de animum inducere y en su realización como verbo de pensamiento, otras dos CVS muy productivas en latín, in animo habere e in animo esse influyeron a su vez en el desarrollo de in animum inducere, con la que comparten estructura sintáctica (en los tres casos animum forma parte de un sintagma preposicional) y contenido semántico. Y es que in animo habere (34) e in animo esse (35) se comportan fundamentalmente como verbos de intención, acompañados regularmente de un infinitivo prolativo:

(34a) Lucceium scito consulatum habere in animo statim petere («Has de saber que Luceyo tiene la intención de presentarse inmediatamente a cónsul», Cic., Att. I 17.11).

(34b) Is nuntiat L. Domitium ... habuisse in animo proficisci Corfinio a. d. V Id. Febr. («Me anuncia que Lucio Domicio ... tiene intención de abandonar Corfinio el 9 de febrero», Cic., Att. VIII 11a.1).

${ }^{25}$ Mucho mayor que animum inducere: en Plauto se documentan 57 ejemplos de animum aduertere, frente a solo 10 de animum inducere. Cf. Baños 2012, p. 48.

${ }^{26}$ Cf. nota 17. A excepción de Plauto y Terencio, el resto de autores arcaicos (Catón, Lucilio, Escipión Emiliano) solo documenta animum inducere. Cf. §. II.1 y los datos desglosados del Cuadro (2). 
(35a) Caesari nuntiatur Heluetiis esse in animo per agrum Sequanorum et Haeduorum iter in Santonum fines facere («Avisan a César de que los helvecios tienen intención de pasar por el país de los secuanos y heduos al de los santonos»,, Caes., Gall. I 10.1).

(35b) Mihi autem erat in animo iam, ut antea ad te scripsi, ire in Epirum («Mi intención ahora es, como ya te he escrito, ir a Epiro», Cic., Att. III 21.1).

En efecto, Kühner y Stegmann (1914, pp. 491-492) citan in animo habere e in animo esse, junto con statuo, constituo, instituo, decerno, etc. entre los verbos y expresiones que llevan un infinitivo prolativo. También Ernout y Thomas (1953, p. 258) recogen ambas CVS entre los «verbes de volonté, pouvoir, d'effort, etc.».

Como se puede ver, la diferencia entre in animo habere e in animo esse no es de significado, sino diatética o de perspectiva (Pompei 2016, p. 104), según la doble posibilidad de expresar la posesión en latín: el infinitivo prolativo es el OD en in animo habere (34) y el sujeto en in animo esse (35).

Desde esta perspectiva, se podría establecer una relación de complementariedad léxica entre acciones referidas a un mismo proceso o, según la terminología de García Hernández 1980, pp. 83-121, una relación intrasubjetiva entre in animum induco y la situación resultativa in animo habeo (el sujeto es el mismo en ambos casos), por un lado, y, por otro, una relación intersubjetiva (el sujeto cambia) entre in animo habeo e in animo [mihi] est:

aliquid in animum induco / aliquid in animo habeo / aliquid in animo mihi est

Llegados a este punto, resulta interesante comparar los datos de frecuencia de estas dos CVS, limitados en este caso al corpus PHI (del latín arcaico hasta Tácito), tal como se recogen en el Cuadro 5:

Cuadro 5: empleo de in animo habere / esse en latín arcaico, clásico y posclásico:

\begin{tabular}{|l|c|c|c|}
\hline & in animo habere & in animo esse & total \\
\hline latín arcaico & 4 & - & 4 \\
\hline latín clásico & 37 & 42 & 79 \\
\hline latín posclásico & 7 & 11 & 18 \\
\hline Total & 48 & 53 & 101 \\
\hline
\end{tabular}


Como se puede ver, in animo habere e in animo esse, CVS apenas documentadas en latín arcaico (no hay ejemplos de in animo esse), presentan en cambio un empleo frecuente desde época clásica, muy superior a partir de ese momento al de in animum inducere - cf. Cuadro 2-. Además, tanto in animo habere como in animo esse presentan de manera sistemática ${ }^{27}$, como forma de complementación oracional, un infinitivo prolativo, tal como ilustran los ejemplos ya citados de (34) y (35).

Desde esta perspectiva, teniendo en cuenta su regularidad semántica (como verbos de intención) y sintáctica (seguidas de un infinitivo prolativo), es más que plausible que in animo habere e in animo esse influyeran sobre in animum inducere, CVS que a partir de época clásica se realiza también y fundamentalmente como un verbo de intención, tal como mostraban los datos del Cuadro 4.

Tampoco es descartable la influencia en sentido inverso, aunque en este caso parece menos determinante: puesto que in animum inducere, desde el latín arcaico, se realiza también como verbo de pensamiento (por influjo en parte de animum inducere y como reflejo en útimo término de la propia polisemia del sustantivo animus), esta doble posibilidad semántica de in animum inducere ayudaría a explicar, por analogía, los dos únicos ejemplos ${ }^{28}$ de in animo habere (no hay ninguno de in animo esse) en que esta CVS se realiza como verbo de pensamiento y presenta, en consecuencia, una completiva de AcI:

semper sic in animo habui, te in meo aere esse propter Lamiae nostri coniunctionem et singularem necessitudinem («siempre tuve la certeza

\footnotetext{
${ }^{27}$ En nuestro corpus se documenta un único ejemplo de $u t+$ subj.: Praedium quom parare cogitabis, sic in animo habeto: uti ne cupide emas neue opera tua parcas uisere («Cuando estés pensando en adquirir una finca de campo, has de procurar no estar ansioso por comprarla y no escatimar esfuerzos en examinarla», Cato, agr. I 1.1).

${ }^{28}$ Otro ejemplo posible es habeasque $<$ in $>$ animo, $m<i>$ admodum causam graue $<m>$ fore («convéncete de que me será enteramente necesaria la causa», Lucil. 29.903), pero presenta problemas de crítica textual. En cambio, en un pasaje como hoc neque ipse transire habebat in animo neque hostes transituros existumabat («Ni tenía intención él mismo [Labieno] de atravesarlo ni creía que los enemigos fueran a hacerlo», Caes., Gall. VI 7.5), el hecho de que se coordine in animo habebat con existimabat no es razón suficiente para sostener que in animo habere «becomes a sort of uerbum putandi» (Pompei 2016, p. 104). Precisamente in animo habere, como verbo de intención, presenta un infinitivo prolativo (transire), mientras que existumabat, como verbo de pensamiento, presenta una completiva de AcI (hostes transituros [esse]), una diferencia que he reflejado también en la traducción al español.
} 
de que te contaba en mi haber a causa de la especial amistad que nos liga a nuestro querido Lamia», Cic., fam. XIII 62.1).

si maritus Liuiae quaereretur, haberet in animo amicum sola necessitudinis gloria usurum («así, si se buscaba un marido para Livia, le rogaba que tuviera en su mente al amigo que de aquel parentesco solo aprovecharía la gloria», Tac., ann. IV 39).

A modo de resumen, en el siguiente cuadro aparecen reflejadas de manera gráfica las posibles influencias analógicas (indicadas por el sentido de las fechas) entre las distintas CVS con animum que he planteado como hipótesis. Además, de acuerdo con los datos de frecuencia y evolución diacrónica comentados y recogidos en los Cuadros 2 y 4, se señala en cada caso cuál pudo ser el valor semántico primario o secundario (entre corchetes) de cada CVS, según se realicen como verbos de pensamiento o como verbos de intención y esfuerzo:

Cuadro 6: valores semánticos e influencias analógicas entre las distintas colocaciones con animum

\begin{tabular}{|c|c|c|}
\hline & $\mathrm{CVS}=$ verbo de pensamiento & CVS $=$ verbo de intención \\
\hline sentido primario & \multirow{3}{*}{$\begin{array}{c}\text { animum aduertere } \\
\text { animum inducere } \\
\text { [in animum inducere }] \\
\text { [in animo habere }]\end{array}$} & \multirow{3}{*}{$\begin{array}{c}\text { in animo habere / in animo esse } \\
\text { in animum inducere } \\
{[\text { animum inducere }]}\end{array}$} \\
\hline & & \\
\hline sentido secundario & & \\
\hline
\end{tabular}

\section{Conclusiones}

Para finalizar, me gustaría destacar algunas de las conclusiones de este artículo:

(i) Animum inducere e in animum inducere son dos construcciones con verbo soporte en origen sintácticamente distintas, derivadas del marco predicativo triargumental de un verbo transitivo de movimiento como inducere. En cada una animum ocupa casillas argumentales diferentes: la del OD en animum inducere y la del tercer argumento en in animum inducere. Ahora bien, desde el momento en que se gramaticalizan como CVS, su sentido unitario ('decidir', 'considerar') hace que se entienden como predicados equivalentes, ya que presentan, además, desde sus primeros testimonios en 
latín arcaico, el mismo tipo de complementación oracional: ut/ne + subjuntivo, infinitivo prolativo y AcI (§ I).

(ii) Desde un punto de vista diacrónico, los datos muestran una clara evolución en el empleo de cada CVS (§ II): animum inducere es la CVS más frecuente en latín arcaico, pero su empleo decrece progresivamente en latín clásico y posclásico en favor de in animum inducere. Estos datos, unidos al mayor grado de fijación formal de animum inducere (§ III.1), al hecho de presentar ejemplos de incorporación sintáctica (§ III.2) y a que es la única CVS documentada en inscripciones arcaicas, invitan a pensar que su gramaticalización fue anterior a la de in animum inducere.

(iii) Las dos CVS presentan, desde época arcaica, dos realizaciones semánticas distintas, que actualizan dos significados de animus ('pensamiento', 'mente', por un lado, e 'intención', 'ánimo', por otro) y que están asociadas además a diferentes estructuras de complementación: como verbos de pensamiento las dos CVS presentan un AcI mientras que como verbos de intención y esfuerzo documentan completivas introducidas con $u t+$ subj. o un infinitivo prolativo. La primera de estas realizaciones, ignorada por las gramáticas latinas, es sobre todo frecuente en latín arcaico, mientras que desde época clásica la realización fundamental de ambas CVS es como verbos de intención o esfuerzo. Esta polisemia de las dos CVS se vio sin duda favorecida por la existencia de verbos como censeo, decerno o statuo, que presentan también esta doble realización semántica como predicados de pensamiento o de esfuerzo (§ III.4).

(iv) En la génesis, desarrollo, contenidos semánticos y estructuras sintácticas de animum inducere e in animum inducere influyeron también otras CVS como animum aduertere, in animo habere e in animo esse (§ IV). La primera, la más frecuente y con un alto grado de gramaticalización, presenta como forma de complementación un AcI e influyó sin duda en animum inducere y en su realización inicial como un predicado fundamentalmente cognitivo, mientras que in animo habere / esse, como predicados de intención, guardan relación, sintáctica y semántica, con in animum inducere, que desde época clásica acentúa precisamente este valor semántico.

(v) Por último, y más allá de sus distintos orígenes, frecuencia de empleo y evolución diacrónica, de influencias y de analogías, es incuestionable que animum inducere e in animum inducere se entienden, desde época arcaica, como predicados equivalentes, lo que explica a su vez algunos problemas de crítica textual. Esta equivalencia es un argumento más para defender la necesidad de analizar de manera conjunta todas las colocaciones verbo-nominales en latín, y 
no solo ni fundamentalmente aquellas en las que el sustantivo predicativo configura una CVS prototípica como OD del verbo soporte (bellum gerere, impetum facere, operam dare, gratias agere). En definitiva, tan construcción con verbo soporte es animum inducere como in animum inducere.

\section{BIBLIOGRAFÍA}

Baños, J. M. (2012): «Verbos soporte e incorporación sintáctica en latín: el ejemplo de ludos facere», Revista de Estudios Latinos 12, pp. 37-57.

Baños, J. M. (2016): «Las construcciones con verbo soporte en latín: sintaxis y semántica», en Borrell, E. et al. (eds.), Omnia mutantur: canvi, transformació $i$ pervivència en la cultura clàssica, en les seves llengües $i$ en el seu llegat, vol. II, Barcelona, pp. 15-39.

Baños, J. M. (2018): «Las construcciones con verbo soporte en latín: una perspectiva diacrónica», en Bodelot, C. y Spevak, O. (eds.), Les constructions à verb support en latin, Clermont-Ferrand, pp. 21-52.

Baños, J. M. (2021a): «Support verbs constructions in Plautus and Terence», en Adams, J. N. et al. (eds.), Early Latin: Constructs, Diversity, Reception, Cambridge.

Baños, J. M. (2021b): «¿Animum inducere o in animum inducere? A propósito de dos pasajes de Cicerón (Cluent. 45; Sulla 83)», Latomus (en prensa).

Baños, J. M. y Jiménez López, M. D. (2017): “'Odiar’ en el Nuevo Testamento (odi, odio sum, odio habeo): traducción y construcciones con verbo soporte en la Vulgata», Euphrosyne 45, pp. 59-78.

Bodelot, C. (1995): «Propositions complétives et construction appositionnelle en latin: ébauche de synthèse», Revue de Philologie 69 (1), pp. 39-73.

Clark, A. C. (1905): M. Tulli Ciceronis Orationes pro Sex. Roscio, de Imperio Cn. Pompei, pro Cluentio, in Catilinam, pro Murena, pro Caelio, Oxford.

Clark, A. C. (1911): M. Tulli Ciceronis Orationes pro Tullio, pro Fonteio, por Sulla, pro Archia, pro Plancio, pro Scauro, Oxford.

Ernout, A. y Thomas, F. (1953): Syntaxe Latine, París.

Früchtel, L. (1931): M. T. Ciceronis scripta quae manserunt omnia (fasc. 15), Leipzig. Fruyt, M. 1990: «La formation des mots par agglutination en latin», Bulletin de la Societé de Linguistique de Paris 85, pp. 173-209.

Fugier, H. (1994): «Le verbe latin 'incorpore'-t-il ses compléments?», en Herman, J. (ed.), Linguistic Studies on Latin, Ámsterdam, pp. 75-90.

Gaffiot, F. (2016): Dictionnaire Latin-Français (nouvelle édition corrigée et augmentée), París.

García Hernández, B. (1980): Semántica estructural y lexemática del verbo, Reus. Glare, P. G. W. (1968): Oxford Latin Dictionary, Oxford. 
Gross, G. (2004): «Pour un Bescherelle de prédicats nominaux», en Gross, G. y de Pontonx, S. (eds.), Verbes supports: Nouvel état des lieux (Lingvisticae Investigationes 27 (2), pp. 343-358.

Hoffmann, R. (1996): «Funktionsverbgefüge im Lateinischen», en Bammesberger, A. y Heberlein, F. (eds.), Akten des VIII internationalen Kolloquiums zur lateinischen Linguistik, Heidelberg, pp. 200-212.

Hofmann, J. B. y Szantyr, A. (1965): Lateinische Syntax und Stilistik mit dem allgemeinen Teil der lateinischen Grammatik, Múnich.

Kasten, H. (1949): M. Tulli Cuceronis Oratio pro Sulla. Oratio por Archia poeta, Leipzig

Keil, H. (1878): Grammatici Latini. Vol. VII. Scriptores de Ortographia.

Kühner, R. y Stegmann, C. (1914): Ausführliche Grammatik der lateinischen Sprache, Hannover.

Lewis, Ch. y Short, Ch. (1879): A Latin Dictionary, Nueva York.

López Martín, I. (2019): «L'evoluzione diacronica nelle costruzioni a verbo supporto: l'esempio di ludus», en Pompei, A. y Mereu, L. (eds.), Verbi supporto: fenomeni e teorie, Múnich, pp. 65-80.

Martín Rodríguez, A. M. (2018): «Les emplois de dare comme verbe support: une réévaluation», en Bodelot, C. y Spevak, O. (eds.), Les constructions à verb support en latín, Clermont-Ferrand, pp. 149-168.

Mendózar, J. (2020): «Las construcciones con verbo soporte en latín. Estado de la cuestión», Tempus 47, pp. 7-48.

Pinkster, H. (1995): Sintaxis y semántica del latín, Madrid.

Pinkster, H. (2015): The Oxford Latin Syntax. The Simple Clause, Oxford.

Pinkster, H. (2021): The Oxford Latin Syntax, Part 2: Complex Sentences and Discourse Phenomena, Oxford.

Pompei, A. (2016): «Construction Grammar and Latin: The Case of habeo», Pallas 102, pp. 99-108.

Rosén, H. (2020): «Composite Predicates in the Layers of Latin», Journal of Latin Linguistics 19 (2), pp. 231-279.

Spevak, O. (2018): «Les constructions à verbe support dans les textes normatifs», en Bodelot, C. y Spevak, O. (eds.), Les constructions à verb support en latin, Clermont-Ferrand, pp. 207-220.

Sylvius, F. (1531): Pro P. Sylla M.T. Ciceronis Oratio, cum F. Sylvii Ambiani commentariis, París.

Tur, C. (2019): Sintaxis y semántica de los nombres de sentimiento en latín: empleos adverbales y colocaciones, Tesis Doctoral, Madrid, Universidad Complutense de Madrid.

Fecha de recepción de la primera versión del artículo: 07/12/2020

Fecha de aceptación: 16/02/2021

Fecha de recepción de la versión definitiva: 10/04/2021 